\title{
Formação de Professores de Química no Contexto da Educação Inclusiva
}

\section{Formation of Teachers of Chemistry in the Context of Inclusive Education}

\author{
Tatiane Estácio de Paula ${ }^{a}$; Orliney Maciel Guimarães ${ }^{\mathrm{a}}$; Camila Silveira da Silva \\ a Departamento de Química, Universidade Federal do Paraná, Curitiba, Brasil - tatianeestaciodepaula@gmail.com, \\ orli.guimaraes@gmail.com, camila@quimica.ufpr.br
}

\section{Palavras-chave: \\ Necessidades formativas. \\ Deficiência visual. \\ Professores de química}

\section{Keywords:}

Training needs. Visual deficiency. Chemistry teachers.
Resumo: O presente trabalho discute sobre a formação de professores de Química no contexto da educação inclusiva. As fontes de informação compõem-se do levantamento das produções nacionais contemplando: periódicos, eventos nacionais de Ensino de Química e de Ensino de Ciências e dissertações e teses dos programas de pós-graduação em nível nacional. Além da realização de entrevistas semiestruturadas com três pesquisadores da área de Educação em Ciências do Brasil, que têm produções voltadas para a Educação Inclusiva. A análise dos dados foi realizada com base na metodologia de Análise Textual Discursiva. Constatamos que o processo formativo docente demanda orientações sobre o respeito à diversidade, na avaliação e na metodologia, bem como conhecimentos sobre as categorias de deficiência para propor adaptações com intuito de atender a diversidade de alunos presentes nas instituições escolares.

Abstract: The present work discusses the educational needs of teachers of Chemistry in the context of inclusion of students with visual impairment. The sources of information are comprised of the survey of national productions including: periodicals, national events of Teaching Chemistry and Science Teaching and the dissertations and theses of graduate programs at the national level. In addition to conducting semi-structured interviews with three researchers in the area of Science Education in Brazil, which has productions focused on Inclusive Education. Data analysis was performed based on Discursive Textual Analysis methodology. We found that the teacher training process demands guidelines on respect for diversity, assessment and methodology, as well as knowledge about disability categories to propose adaptations in order to meet the diversity of students present in school institutions 


\section{Introdução}

No contexto nacional, o movimento de Educação Inclusiva foi consolidado mediante a Política Nacional de Educação Especial na Perspectiva da Educação Inclusiva (2008), a qual prevê o "acesso à educação básica, matrícula na rede pública, ingresso nas classes comuns, oferta de atendimento educacional especializado" (BRASIL, 2008), aos alunos com necessidades específicas decorrentes de deficiência, Transtorno Global do Desenvolvimento (TGD), Altas Habilidades/Superdotação (AH/SD). Entretanto, promover acesso em todas as dimensões (instrumentais, atitudinais, metodológicas, arquitetônicas) aos estudantes com deficiência têm se apresentado como um desafio às instituições escolares (SASSAKI, 2005; RODRIGUES, 2008).

Diante desta realidade, os cursos de formação de professores devem atender as demandas da Educação atual para que os docentes possam oferecer aos seus futuros alunos, com e sem deficiência, as condições necessárias para sua formação intelectual, social e moral.

No âmbito da Educação Especial na perspectiva Inclusiva, verificamos que existem necessidades a serem supridas nos cursos de formação de professores, pois, esses se julgam, na maioria das vezes, sem uma formação adequada, que lhes permita atender e incluir os estudantes com necessidades específicas, fato que geralmente ocasiona o fenômeno da pseudoinclusão, que corresponde à presença física do aluno em sala de aula, sem que o mesmo participe de modo ativo no processo de aprender (PIMENTEL, 2012).

Deste modo, para além de atingir o que é imposto pela Educação Especial na perspectiva inclusiva, acreditamos e defendemos a Inclusão, como um aspecto social e educacional de grande relevância e por esse motivo, consideramos necessário que as práticas de formação docente sejam reavaliadas e reformuladas, a fim de contemplar aspectos que proporcionem ao docente uma atuação fundamentada e crítica diante da diversidade de alunos para incluí-los respeitando as suas particularidades e desta forma, atender as necessidades formativas que surgem frente às demandas da Educação Inclusiva.

Nesse sentido, utilizamos como base trabalhos (ARANHA, 2002; DUK, 2006; MINETTO, 2008; VITALIANO; MANZINI, 2010; ANTUNES; GLAT, 2011; BENITE, 2011; CAMARGO, 2012, OLIVEIRA, 2012; PIMENTEL, 2012) que discutem os conhecimentos necessários a serem abordados nas práticas de formação de professores do ensino regular, em busca de incluir os alunos com necessidades específicas advindas de alguma deficiência física ou intelectual. Estes conhecimentos envolvem o conhecer as necessidades específicas dos alunos; saber realizar a flexibilização do currículo de acordo com as necessidades específicas de aprendizagem; saber avaliar o processo de aprendizagem, e atuar em equipe com os pais e demais profissionais do atendimento educacional especializado. 
Portanto, assim como na formação dos demais profissionais da Educação, tais conhecimentos devem fazer parte dos cursos de Licenciaturas em Química/Ciências, visto que de acordo com os Parâmetros Curriculares Nacionais para o Ensino Médio (2000) o Ensino Médio faz parte da etapa final da educação básica e isso significa:

[...] assegurar a todos os cidadãos a oportunidade de consolidar e aprofundar os conhecimentos adquiridos no Ensino Fundamental; aprimorar o educando como pessoa humana; possibilitar o prosseguimento de estudos; garantir a preparação básica para o trabalho e a cidadania; dotar o educando dos instrumentos que o permitam "continuar aprendendo" tendo em vista o desenvolvimento da compreensão dos "fundamentos científicos e tecnológicos dos processos produtivos" (BRASIL, 2000, p. 9-10).

Nessa perspectiva, espera-se que os conhecimentos construídos na disciplina de Química/Ciências contribuam de modo significativo para o desenvolvimento da capacidade de julgar, avaliar e se posicionar frente às questões sociais que envolvam aspectos voltados a ações políticas e éticas sobre ciência, tecnologia e meio ambiente (SANTOS; MORTIMER, 1999). Assim sendo, torna-se essencial que todos os discentes, independente das necessidades que apresentam, recebam as condições essenciais para agir de forma consciente e crítica para exercer a cidadania plena, fazendo-se necessário para isto o desenvolvimento desse saber por parte do professor.

Diante deste contexto, esse artigo discute os resultados de parte de uma Dissertação de Mestrado, que teve como objetivo principal analisar as necessidades formativas de professores de Química para inclusão de alunos com deficiência visual. No referido estudo foi possível propor e discutir dez necessidades formativas, destacadas a seguir: Conhecer os propósitos da Educação Inclusiva, Conhecer sobre as deficiências; Conhecer as Políticas Públicas e Contexto Histórico da Educação Especial e Inclusiva, Saber Avaliar; Saber trabalhar em equipe; Conhecer os recursos disponíveis que auxiliam no aprendizado de Alunos com Deficiência, Conhecer sobre a deficiência visual do Aluno; Saber vincular os conceitos químicos através de representações que não dependam estritamente da visão; Saber trabalhar com a linguagem matemática e Saber realizar atividades comuns aos alunos com e sem deficiência visual.

Nesse artigo apresentamos e discutimos as cinco primeiras necessidades formativas, que embora tenham emergido de uma pesquisa no âmbito do ensino de Química para alunos com Deficiência Visual, consideramos as mesmas relevantes para formação de professores de Ciências em geral, no contexto da Educação Inclusiva. 


\section{Metodologia}

Com a finalidade de estudar as necessidades formativas de professores de Química na perspectiva da Educação Inclusiva, realizamos uma pesquisa empírica, de cunho qualitativo. A escolha pela metodologia qualitativa deve-se ao fato deste tipo de metodologia compreender e descrever os fenômenos sociais, no âmbito em que ocorrem de diversas maneiras diferentes: analisando as experiências de indivíduos ou grupos, por meio de relatos e histórias; examinando as interações e comunicações que estejam se desenvolvendo; investigando documentos ou traços semelhantes de experiências ou interações (LÜDKE; ANDRÉ, 2013).

Deste modo, a fim de recorrer a várias perspectivas sobre um mesmo contexto, contemplamos em nossa pesquisa: a revisão da produção acadêmica nacional na área e o levantamento empírico junto a três pesquisadores que possuíam produções relacionadas à temática da Educação inclusiva no Ensino de Física e de Química, com ênfase na inclusão de alunos com deficiência visual, que foi o foco original dessa pesquisa.

Iniciamos o processo de constituição dos dados realizando uma pesquisa bibliográfica, que compreendeu: artigos publicados em periódicos da área de Ensino e Educação avaliados com o critério Qualis A1, A2, B1 e B2 pela CAPES (quadriênio vigente 2013-2016), em trabalhos presentes nas atas do Encontro Nacional de Ensino de Química (ENEQ) e do Encontro Nacional de Pesquisa em Educação em Ciências (ENPEC) e teses e dissertações que constavam no portal da CAPES, no ano de 2015.

Nesta busca foram utilizados alguns termos como: deficiência visual; cegos; Ensino de Química para cegos; Ensino de Ciências para alunos com deficiência visual; Educação Inclusiva no Ensino de Ciências; Formação de professores de Ciências e Educação Inclusiva, Inclusão escolar. A seleção dos trabalhos foi realizada mediante a análise dos títulos, das palavras-chave e da leitura dos resumos (LIPPE; CAMARGO, 2009). Dessa forma, o levantamento bibliográfico realizado na referida base dados, nos permitiu categorizar as necessidades formativas para o ensino de Química para alunos com deficiência visual discutidas nesses trabalhos. Portanto, esse levantamento não teve as características de uma pesquisa do tipo Estado da Arte (FERREIRA, 2002).

Em relação aos periódicos foram acessadas apenas as revistas nacionais disponíveis on-line. O período escolhido para iniciar o recorte temporal do levantamento bibliográfico, deve-se ao fato ter sido a partir de 2004 que os eventos ENEQ e ENPEC passaram a contemplar a temática específica da Educação Inclusiva. A etapa da realização do levantamento bibliográfico se deu no período de março a setembro de 2014.

$\mathrm{O}$ resultado da pesquisa de dissertações e teses encontradas no sistema de busca no portal da CAPES pode ser verificado no Quadro 1. 
Quadro 1 - Dissertações e Teses encontradas no portal da CAPES em 2015

\begin{tabular}{|c|c|c|c|}
\hline Título/ Identificação & Autor/Orientador & Instituição & Ano \\
\hline $\begin{array}{l}\text { Proposta de Guia para apoiar a prática } \\
\text { pedagógica de professores de Química em } \\
\text { sala de aula inclusiva com alunos que } \\
\text { apresentam Deficiência Visual (DT 1) }\end{array}$ & $\begin{array}{l}\text { Rejane Ferreira } \\
\text { Machado Pires } \\
\text { Prof. Dr. Gerson de } \\
\text { Souza Mól }\end{array}$ & $\begin{array}{c}\text { Universidade de Brasília } \\
\text { - UNB }\end{array}$ & 2010 \\
\hline $\begin{array}{l}\text { O Ensino de Ciências e Deficiência } \\
\text { Visual: Uma investigação das percepções } \\
\text { das professoras de ciências e da sala de } \\
\text { recursos com relação à inclusão. (DT 2) }\end{array}$ & $\begin{array}{l}\text { Eliza Márcia de O. } \\
\text { Lippe } \\
\text { Prof. Dr. Eder Pires } \\
\text { de Camargo }\end{array}$ & $\begin{array}{l}\text { Universidade Estadual } \\
\text { Paulista "Júlio de } \\
\text { Mesquita Filho" - } \\
\text { UNESP }\end{array}$ & 2010 \\
\hline $\begin{array}{c}\text { Formação do professor e docência em } \\
\text { química em rede social: estudos sobre a } \\
\text { inclusão escolar e o pensar comunicativo } \\
\text { (DT 3) }\end{array}$ & $\begin{array}{l}\text { Claudio Roberto } \\
\text { Machado Benite } \\
\text { Prof }^{\mathrm{a}} \text { Dr }^{\mathrm{a}} \text { Anna M. } \\
\text { Canavarro Benite }\end{array}$ & $\begin{array}{c}\text { Universidade Federal de } \\
\text { Goiás - UFG }\end{array}$ & 2011 \\
\hline $\begin{array}{l}\text { Formação de professores de Ciências e } \\
\text { Educação Inclusiva em uma instituição de } \\
\text { Ensino Superior em Jataí-GO (DT 4) }\end{array}$ & $\begin{array}{l}\text { Eveline Borges } \\
\text { Vilela-Ribeiro. } \\
\text { Prof }^{\mathrm{a}} \text { Dr }^{\mathrm{a}} \text { Anna M. } \\
\text { Canavarro Benite }\end{array}$ & $\begin{array}{c}\text { Universidade Federal de } \\
\text { Goiás- UFG }\end{array}$ & 2011 \\
\hline $\begin{array}{c}\text { A Formação de Professores de Ciências } \\
\text { Biológicas e a Educação Inclusiva: uma } \\
\text { interface da formação inicial e continuada } \\
\text { (DT 5) }\end{array}$ & $\begin{array}{l}\text { Sandra de Freitas } \\
\text { Paniago Fernandes } \\
\text { Prof }^{\mathrm{a}} \text { Dr }^{\mathrm{a}} \text { Anna M. } \\
\text { Canavarro Benite }\end{array}$ & $\begin{array}{c}\text { Universidade Federal de } \\
\text { Goiás - UFG }\end{array}$ & 2012 \\
\hline
\end{tabular}

Fonte: as autoras, 2015.

Os trabalhos encontrados nas atas disponibilizadas on-line dos eventos ENEQ ${ }^{1}$ e ENPEC estão apresentados no Quadro 2:

Quadro 2 - Trabalhos em Eventos Nacionais (ENEQ e ENPEC) no período de 2004 a 2014

\begin{tabular}{|c|c|c|}
\hline Trabalho/ Identificação & Autor(es) & Ano/Evento \\
\hline $\begin{array}{c}\text { Elaboração de recursos didáticos para o Ensino } \\
\text { de Química para cegos (EQ 1) }\end{array}$ & $\begin{array}{c}\text { MOL, G. S., NEVES, P. R., } \\
\text { RODRIGUES, S., VIDIGAL, } \\
\text { A.; FREITAS, A. }\end{array}$ & XII ENEQ - 2004 \\
\hline $\begin{array}{c}\text { Os sentidos da/na experimentação no ensino: um } \\
\text { estudo sobre ensino de Química para crianças } \\
\text { com baixa visão (EQ 2) }\end{array}$ & ANDRADE, J.J., SMOLKA, A. & XIII ENEQ - 2006 \\
\hline $\begin{array}{c}\text { Dificuldades de alunos com deficiência visual na } \\
\text { disciplina Química (EQ 3) }\end{array}$ & MÓL, G. S. RAPOSO, P. & XIII ENEQ - 2006 \\
PIRES, R.F.M.; BRASIL, & \\
\hline $\begin{array}{c}\text { Parceria colaborativa na formação de professores } \\
\text { de Ciências: a Educação Inclusiva em questão } \\
\text { (EQ 4) }\end{array}$ & $\begin{array}{c}\text { BENITE, A. M. C.; NAVES, A. } \\
\text { PEREIRA, L. S. LOBO, P. }\end{array}$ & XIV ENEQ - 2008 \\
\hline $\begin{array}{c}\text { Ressignificando a Formação de professores de } \\
\text { Química para a Educação Especial e Inclusiva: } \\
\text { Uma história de parcerias (EQ 5) }\end{array}$ & $\begin{array}{c}\text { RETONDO C. G., SILVA, G. } \\
\text { A M. }\end{array}$ & XIV ENEQ - 2008 \\
\hline A Aprendizagem Química para alunos que & PEREIRA, S.L.P.O.; SILVA, & XV ENEQ - 2010 \\
\hline
\end{tabular}

${ }^{1}$ Com exceção dos ENEQs dos anos de 2004 e 2006, cujos arquivos foram disponibilizados e acessados em CDs 


\begin{tabular}{|c|c|c|}
\hline apresentam deficiência visual (EQ 6) & J.L.P.B. & \\
\hline $\begin{array}{c}\text { Formação de professores de Ciências para a } \\
\text { Inclusão Escolar: estudos sobre a produção de } \\
\text { diálogos (EQ 7) }\end{array}$ & $\begin{array}{l}\text { VILELA-RIBEIRO, E. B.; } \\
\text { BENITE, A.M. }\end{array}$ & XV ENEQ - 2010 \\
\hline $\begin{array}{c}\text { Reflexões de uma licenciada em Química sobre a } \\
\text { Inclusão Escolar de alunos com Deficiência } \\
\text { Visual (EQ 8) }\end{array}$ & ARAGÃO, A.S.; SILVA, G. M. & XV ENEQ - 2010 \\
\hline $\begin{array}{c}\text { Inclusão: concepções dos professores de Ciências } \\
\text { Naturais da Escola Aloysio Chaves- } \\
\text { Concórdia/PA (EQ 9) }\end{array}$ & REIS, E. S.; SILVA, L. P. & XV ENEQ - 2010 \\
\hline $\begin{array}{c}\text { Propostas de atividades experimentais elaboradas } \\
\text { por futuros professores de Química para alunos } \\
\text { com deficiência visual (EQ 10) }\end{array}$ & $\begin{array}{l}\text { NUNES, B.C.; DUARTE, C.B.; } \\
\text { PADIM, D.F.; MELO, I.C.; } \\
\text { ALMEIDA, J.L.; TEIXEIRA } \\
\text { JUNIOR, J.G. }\end{array}$ & XV ENEQ - 2010 \\
\hline $\begin{array}{l}\text { Conhecimento científico, conhecimento cotidiano } \\
\text { e a construção dos nexos nos processos de } \\
\text { elaboração conceitual (EQ 11) }\end{array}$ & ANDRADE, J. J. & XV ENEQ - 2010 \\
\hline $\begin{array}{c}\text { Rede Goiana de Pesquisa em Educação } \\
\text { Especial/Inclusiva: Formando Professores de } \\
\text { Ciências/Química (EQ 12) }\end{array}$ & $\begin{array}{l}\text { PEREIRA, L.L.S.; BENITE, } \\
\text { A.M.C. }\end{array}$ & XV ENEQ - 2010 \\
\hline $\begin{array}{c}\text { Formação de professores de Ciências para a } \\
\text { Inclusão Escolar: estudos sobre a produção de } \\
\text { diálogos (EQ 13) }\end{array}$ & $\begin{array}{l}\text { VILELA-RIBEIRO, E.V.; } \\
\text { BENITE, A.M.C. }\end{array}$ & XV ENEQ - 2010 \\
\hline $\begin{array}{l}\text { Considerações sobre o Ensino de Química e a } \\
\text { Inclusão Escolar (EQ 14) }\end{array}$ & $\begin{array}{l}\text { SILVA, A.P.T.; PASSOS, I. } \\
\text { N.M.; FIELD`S, K.A.P.; } \\
\text { ANDRADE, K.S.; BORGES, } \\
\text { L.C.M.; BENITE, A.M.C. }\end{array}$ & XV ENEQ - 2010 \\
\hline $\begin{array}{c}\text { Ensino de Química para Deficientes Visuais: } \\
\text { Sobre Intervenção Pedagógica em Instituição de } \\
\text { Apoio (EQ 15). }\end{array}$ & $\begin{array}{l}\text { FIELD'S, K. A. P.; } \\
\text { CAVALCANTE, K. L.; } \\
\text { MORAIS, W.C.S.; BENITE, } \\
\text { C.R.M.; BENITE, } \\
\text { A. M.C }\end{array}$ & XV ENEQ -2010 \\
\hline $\begin{array}{l}\text { Formação de professores de Química na } \\
\text { perspectiva da inclusão de alunos cegos } \\
\text { (EQ 16) }\end{array}$ & $\begin{array}{l}\text { REGIANI, A. M.; ALMEIDA, } \\
\text { M. P. }\end{array}$ & XVI ENEQ - 2012 \\
\hline $\begin{array}{c}\text { Ensino de Química para Deficientes Visuais: } \\
\text { Sobre Intervenção Pedagógica em Instituição de } \\
\text { Apoio (EQ 17) }\end{array}$ & $\begin{array}{c}\text { FIELD'S K. A. P.; } \\
\text { CAVALCANTE, K. L.; } \\
\text { MORAIS, W.C.S.; BENITE, } \\
\text { C.R.M.; BENITE, A. M.C }\end{array}$ & XVI ENEQ - 2012 \\
\hline $\begin{array}{l}\text { O Ensino de Química para deficientes visuais: } \\
\text { concepções dos formadores de professores acerca } \\
\text { da Inclusão (EQ 18) }\end{array}$ & $\begin{array}{l}\text { XAVIER, L. L.; SILVA, P. } \\
\text { H.C.; FÉLIX, J. R.; BENITE, C. } \\
\text { R.M.; BENITE, A. M. C. }\end{array}$ & XVI ENEQ - 2012 \\
\hline $\begin{array}{c}\text { Percepção de Professores Universitários sobre o } \\
\text { Ensino de Química à Alunos com Deficiência } \\
\text { Visual (EQ 19) }\end{array}$ & $\begin{array}{l}\text { MÓL, G. S. TEIXEIRA, L.V.; } \\
\text { ARAÚJO, S. G.; EUSTÓGIO, } \\
\text { A. M. RIBEIRO, E. M. }\end{array}$ & XVI ENEQ - 2012 \\
\hline $\begin{array}{l}\text { O professor de Química e a deficiência visual } \\
\text { (EQ 20) }\end{array}$ & $\begin{array}{l}\text { LIMA, A. A.S.; REGIANI, A. } \\
\text { M.; COSTA, J. S.; FREITAS, } \\
\text { R. C. V.; SILVA, T.F. } \\
\end{array}$ & XVII ENEQ - 2014 \\
\hline $\begin{array}{l}\text { Reflexões sobre a prática pedagógica do docente } \\
\text { cego no ensino de Química para alunos cegos } \\
\text { (EQ 21) }\end{array}$ & $\begin{array}{l}\text { MARIANO, L. S.; REGIANI, } \\
\text { A.M. }\end{array}$ & XVII ENEQ - 2014 \\
\hline $\begin{array}{c}\text { Estudos sobre a formação de modelos mentais de } \\
\text { compostos orgânicos no contexto da deficiência } \\
\text { visual (EQ 22) }\end{array}$ & $\begin{array}{l}\text { COSTA, A. C.; RAMOS, A. C. } \\
\text { S.; CAMILO, W. M.; MORAIS, } \\
\text { W.C.S.; BENITE, C.R.M. }\end{array}$ & XVII ENEQ - 2014 \\
\hline $\begin{array}{l}\text { Produção de materiais didáticos acessíveis para o } \\
\text { Ensino de Química Orgânica Inclusivo }\end{array}$ & $\begin{array}{l}\text { PAULO, P. R. N.; DELOU, } \\
\text { C.M.C.; BORGES, M. N. }\end{array}$ & XVII ENEQ - 2014 \\
\hline
\end{tabular}




\begin{tabular}{|c|c|c|}
\hline (EQ 23) & & \\
\hline $\begin{array}{l}\text { Análise dos projetos pedagógicos dos cursos de } \\
\text { Licenciatura em Química do Estado do Rio de } \\
\text { Janeiro quanto a perspectiva inclusiva (EQ 24) }\end{array}$ & SANTOS, C. C.; BEJA, A.C.S. & XVII ENEQ - 2014 \\
\hline $\begin{array}{l}\text { Elaboração conceitual na formação inicial de } \\
\text { professores: linguagem, deficiência e relações de } \\
\text { ensino em foco (EQ 25) }\end{array}$ & $\begin{array}{l}\text { ANDRADE, J. J.; ABREU, } \\
\text { D.G.; LOURENÇO, A. J.; } \\
\text { MELLO, M.C.L. }\end{array}$ & XVII ENEQ - 2014 \\
\hline $\begin{array}{l}\text { Iniciação à Docência em Química: O Diário } \\
\text { Virtual Coletivo na aproximação entre Escola e } \\
\text { Educação Superior (EQ 26) }\end{array}$ & COELHO, J. C. et al. & XVII ENEQ - 2014 \\
\hline $\begin{array}{c}\text { Dificuldades e alternativas iniciais encontradas } \\
\text { por licenciandos para a elaboração de atividades } \\
\text { de ensino de Física para alunos com deficiência } \\
\text { visual (EC 1) }\end{array}$ & CAMARGO, E. P.; NARDI, R. & V ENPEC - 2005 \\
\hline $\begin{array}{l}\text { Ensino de Física e alunos com deficiência visual: } \\
\text { Análise e Proposta de Procedimentos docentes de } \\
\text { Condução de atividades de ensino (EC 2) }\end{array}$ & CAMARGO, E. P.; SILVA, D & V ENPEC - 2005 \\
\hline $\begin{array}{c}\text { Ensino de óptica para alunos com deficiência } \\
\text { visual: análise de concepções alternativas (EC 3) }\end{array}$ & $\begin{array}{l}\text { ALMEIDA, D. R. V.; MACIEL } \\
\text { FILHO, P.R.; CAMARGO, } \\
\text { E.P.; NARDI, R. }\end{array}$ & V ENPEC - 2005 \\
\hline $\begin{array}{l}\text { Alunos com deficiência visual em um curso de } \\
\text { Química: fatores atitudinais como dificuldades } \\
\text { educacionais (EC 4) }\end{array}$ & $\begin{array}{l}\text { CAMARGO, E. P.; SANTOS, } \\
\text { S.L.R.; NARDI, R. } \\
\text { VERASTZO, E. V. }\end{array}$ & VI ENPEC - 2007 \\
\hline $\begin{array}{c}\text { Ensino de Física à Estudantes Cegos na } \\
\text { Perspectiva dos professores (EC 5) }\end{array}$ & $\begin{array}{c}\text { FERREIRA, A. C.; DICKMAN, } \\
\text { A. G. }\end{array}$ & VI ENPEC - 2007 \\
\hline $\begin{array}{c}\text { O Ensino de Ciências e seus desafios inclusivos: } \\
\text { o olhar de um professor de Química sobre a } \\
\text { diversidade escolar (EC 6) }\end{array}$ & SOUZA, V.C.A.; JUSTI, R. S. & VI ENPEC - 2007 \\
\hline $\begin{array}{c}\text { A Comunicação como barreira à inclusão de } \\
\text { alunos com deficiência visual em aulas de } \\
\text { termologia } \\
\text { (EC 7) }\end{array}$ & $\begin{array}{l}\text { CAMARGO, E. P.; NARDI, R.; } \\
\text { LIPPE, E. M. O }\end{array}$ & VII ENPEC - 2009 \\
\hline $\begin{array}{c}\text { O diário virtual coletivo: um recurso para } \\
\text { investigação da formação de professores de } \\
\text { ciências de deficientes visuais } \\
\text { (EC 8) }\end{array}$ & $\begin{array}{l}\text { BATISTA, M. A. R.S.; } \\
\text { FIELD’S, K. A.; SILVA, L.; } \\
\text { BENITE, A. M.C. }\end{array}$ & VIII ENPEC - 2011 \\
\hline $\begin{array}{c}\text { O Ensino de Modelos Atômicos a deficientes } \\
\text { visuais (EC 9) }\end{array}$ & $\begin{array}{l}\text { RAZUCK, R. C. S.R; } \\
\text { GUIMARÃES, L.B.; ROTTA, } \\
\text { J.C. }\end{array}$ & VIII ENPEC - 2011 \\
\hline $\begin{array}{l}\text { Ensino de Física para deficientes visuais: } \\
\text { Métodos e Materiais utilizados na mudança de } \\
\text { referencial observacional (EC 10) }\end{array}$ & $\begin{array}{l}\text { COSTA, J. J. L.; QUEIROZ, J. } \\
\text { R. O.; FURTADO, W.W. }\end{array}$ & VIII ENPEC - 2011 \\
\hline $\begin{array}{l}\text { O PIBID e a educação inclusiva de alunos com } \\
\text { deficiência visual: materiais manipulativos e } \\
\text { linguagem matemática para o ensino de ciências } \\
\text { (EC 11) }\end{array}$ & $\begin{array}{l}\text { LIBARDI, H.; PEDROSO, A. } \\
\text { P.; MENDES, T. P.; BRAZ, F. } \\
\text { F.; OLIVEIRA, G.A. }\end{array}$ & VIII ENPEC - 2011 \\
\hline $\begin{array}{l}\text { Como pensam os professores de Física de um } \\
\text { colégio público em relação ao Ensino de Física } \\
\text { para deficientes visuais (EC 12) }\end{array}$ & $\begin{array}{c}\text { AGUIAR, M. V. F.; } \\
\text { BARBOSA-LIMA, M.C.A.; }\end{array}$ & VIII ENPEC - 2011 \\
\hline $\begin{array}{c}\text { Sobre identidades culturais na formação de } \\
\text { professores de Química: Em foco a Educação } \\
\text { Inclusiva (EC 13) }\end{array}$ & $\begin{array}{l}\text { BENITE, C. R. M.; VILELA- } \\
\text { RIBEIRO, E.B.; BENITE, A. } \\
\text { M. C. }\end{array}$ & VIII ENPEC - 2011 \\
\hline $\begin{array}{l}\text { Estudos sobre a construção da diversidade na } \\
\text { formação inicial de professores de Ciências: do } \\
\text { discurso de formadores ao currículo escrito }\end{array}$ & $\begin{array}{l}\text { VILELA- RIBEIRO, E. B. } \\
\text { BENITE, A. M. C. }\end{array}$ & VIII ENPEC - 2011 \\
\hline
\end{tabular}




\begin{tabular}{|c|c|c|}
\hline (EC 14) & & \\
\hline $\begin{array}{c}\text { As concepções alternativas dos deficientes } \\
\text { visuais no Ensino de Física (EC 15) }\end{array}$ & $\begin{array}{c}\text { SANTOS, M.C.S.; } \\
\text { PESSANHA, P. R.; SANTOS, } \\
\text { R.; BARBOSA-LIMA, M.C.A. }\end{array}$ & VIII ENPEC - 2011 \\
\hline $\begin{array}{c}\text { Formação de professores de Física inclusivistas: } \\
\text { interdisciplinaridade por si... (EC 16) }\end{array}$ & $\begin{array}{c}\text { BARBOSA-LIMA, M. C.; } \\
\text { CATARINO, G.F.C. }\end{array}$ & IX ENPEC - 2013 \\
\hline $\begin{array}{c}\text { A educação inclusiva e o ensino de Ciências e de } \\
\text { Biologia: a compreensão de professores do } \\
\text { ensino básico e de alunos da licenciatura } \\
\text { (EC 17) }\end{array}$ & DIAS, A. B. & IX ENPEC - 2013 \\
\hline $\begin{array}{c}\text { Análise de uma intervenção pedagógica sobre o } \\
\text { conceito de soluçães no contexto da deficiência } \\
\text { visual (EC 18) }\end{array}$ & BENITE, C. R. M. & IX ENPEC - 2013 \\
\hline $\begin{array}{c}\text { Biológicas e a educação inclusiva: uma interface } \\
\text { da formação inicial e continuada } \\
\text { (EC 19) }\end{array}$ & $\begin{array}{c}\text { FERNANDES, S.F.P.; ROSA, } \\
\text { D.E.G. }\end{array}$ & IX ENPEC - 2013 \\
\hline $\begin{array}{c}\text { A educação inclusiva segundo os graduandos do } \\
\text { curso de Licenciatura em Física, Matemática e } \\
\text { Química da Universidade Estadual de Roraima } \\
\text { (EC 20) }\end{array}$ & PEREIRA, G. A.; RIZATTI, I. & IX ENPEC - 2013 \\
\hline
\end{tabular}

Fonte: as autoras, 2015.

Os artigos encontrados nos periódicos nacionais disponibilizados on-line, podem ser vistos no Quadro 3.

Quadro 3 - Artigos de Periódicos Nacionais disponíveis on-line

\begin{tabular}{|c|c|c|c|c|}
\hline Revista & Título do Artigo/ Identificação & Autor(es) & $\begin{array}{c}\text { Capes- } \\
\text { Qualis } \\
\text { Ensino/E } \\
\text { ducação }\end{array}$ & Ano \\
\hline Ciência e Educação & $\begin{array}{c}\text { O Ensino de Física para deficientes visuais a } \\
\text { partir de uma perspectiva fenomenológica } \\
\text { (ART 1) }\end{array}$ & $\begin{array}{l}\text { COSTA, L. G.; } \\
\text { NEVES, M. C. } \\
\text { D.; BARONE, D. } \\
\text { A. C. }\end{array}$ & A1/A1 & 2006 \\
\hline Ciência e Educação & $\begin{array}{c}\text { Formação inicial de professores de Física: a } \\
\text { questão da inclusão de alunos com } \\
\text { deficiências visuais no ensino regular } \\
\text { (ART 2) }\end{array}$ & $\begin{array}{l}\text { LIMA, M.C. B.; } \\
\text { CASTRO, G. F. }\end{array}$ & A1/A1 & 2012 \\
\hline Ciência e Educação & $\begin{array}{l}\text { O ensino de física no contexto da deficiência } \\
\text { visual: análise de uma atividade estruturada } \\
\text { sobre um evento sonoro - posição de } \\
\text { encontro de dois móveis (ART 3) }\end{array}$ & $\begin{array}{l}\text { CAMARGO, E. } \\
\text { P.; SILVA, D. }\end{array}$ & A1/A1 & 2006 \\
\hline Ciência e Educação & $\begin{array}{c}\text { Inclusão de uma aluna cega em um curso de } \\
\text { licenciatura em Química (ART 4) }\end{array}$ & $\begin{array}{l}\text { REGIANI, A. M.; } \\
\text { MÓL, G.S. }\end{array}$ & A1/A1 & 2013 \\
\hline Ciência e Educação & $\begin{array}{l}\text { A Comunicação como barreira á inclusão de } \\
\text { alunos com deficiência visual em aulas de } \\
\text { mecânica (ART 5) }\end{array}$ & $\begin{array}{l}\text { CAMARGO, E. } \\
\text { P. }\end{array}$ & A1/A1 & 2010 \\
\hline $\begin{array}{l}\text { Revista Brasileira } \\
\text { de Educação } \\
\text { Especial }\end{array}$ & $\begin{array}{l}\text { Ensino de conceitos físicos de termologia } \\
\text { para alunos com deficiência visual: } \\
\text { dificuldades e alternativas encontradas por } \\
\text { licenciandos para o planejamento de } \\
\text { atividades (ART 6) }\end{array}$ & $\begin{array}{l}\text { CAMARGO, E. } \\
\text { P.; NARDI, R. }\end{array}$ & A1/A2 & 2006 \\
\hline $\begin{array}{l}\text { Revista Brasileira } \\
\text { de Educação } \\
\text { Especial }\end{array}$ & $\begin{array}{c}\text { O emprego de linguagens acessíveis para } \\
\text { alunos com deficiência visual em aulas de } \\
\text { Óptica (ART 7) }\end{array}$ & $\begin{array}{l}\text { CAMARGO, } \\
\text { E.P.; NARDI, R. }\end{array}$ & $\mathrm{A} 1 / \mathrm{A} 2$ & 2008 \\
\hline
\end{tabular}




\begin{tabular}{|c|c|c|c|c|}
\hline $\begin{array}{l}\text { Revista Brasileira } \\
\text { do Ensino de Física }\end{array}$ & $\begin{array}{l}\text { Dificuldades e alternativas encontradas por } \\
\text { licenciandos para o planejamento de } \\
\text { atividades de ensino de óptica para alunos } \\
\text { com deficiência visual (ART 08) }\end{array}$ & $\begin{array}{c}\text { CAMARGO, } \\
\text { E.P.; NARDI, R. }\end{array}$ & $\mathrm{A} 1 / \mathrm{B} 2$ & 2007 \\
\hline $\begin{array}{l}\text { Revista Brasileira } \\
\text { do Ensino de Física }\end{array}$ & $\begin{array}{c}\text { A comunicação como barreira na inclusão o } \\
\text { de alunos com deficiência visual em aulas de } \\
\text { optica (ART 09) }\end{array}$ & $\begin{array}{l}\text { CAMARGO, } \\
\text { E.P.; NARDI, R; } \\
\text { VERASZTO, E. } \\
\text { V. }\end{array}$ & $\mathrm{A} 1 / \mathrm{B} 2$ & 2008 \\
\hline $\begin{array}{l}\text { ENSAIO - } \\
\text { Pesquisa em } \\
\text { Educação em } \\
\text { Ciências }\end{array}$ & $\begin{array}{l}\text { O Ensino não formal e a formação de um } \\
\text { professor de física para deficientes visuais } \\
\text { (ART 10) }\end{array}$ & $\begin{array}{l}\text { BARBOSA- } \\
\text { LIMA, M.C.A.; } \\
\text { GONÇALVES, } \\
\text { C.O. }\end{array}$ & $\mathrm{A} 2 / \mathrm{A} 2$ & 2014 \\
\hline $\begin{array}{c}\text { ENSAIO - } \\
\text { Pesquisa em } \\
\text { Educação em } \\
\text { Ciências } \\
\end{array}$ & $\begin{array}{c}\text { Contextos comunicacionais adequados e } \\
\text { inadequados à inclusão de alunos com } \\
\text { deficiência visual em aulas de mecânica } \\
\text { (ART 11) }\end{array}$ & $\begin{array}{c}\text { CAMARGO, } \\
\text { E.P.; NARDI, R. }\end{array}$ & A2/A2 & 2010 \\
\hline $\begin{array}{c}\text { ENSAIO - } \\
\text { Pesquisa em } \\
\text { Educação em } \\
\text { Ciências }\end{array}$ & $\begin{array}{c}\text { As representações sociais dos licenciandos } \\
\text { de física referentes à inclusão de deficientes } \\
\text { visuais (ART 12) }\end{array}$ & $\begin{array}{l}\text { BARBOSA- } \\
\text { LIMA, M.C.A.; } \\
\text { MACHADO, } \\
\text { M.A.D. }\end{array}$ & A2/A2 & 2011 \\
\hline $\begin{array}{l}\text { Química Nova na } \\
\text { Escola }\end{array}$ & $\begin{array}{l}\text { A Educação Inclusiva na Formação de } \\
\text { Professores e no Ensino de Química: A } \\
\text { Deficiência Visual em Debate (ART 13) }\end{array}$ & $\begin{array}{l}\text { GONÇALVE, } \\
\text { F.P.. et. al. }\end{array}$ & $\mathrm{B} 1 / \mathrm{B} 2$ & 2013 \\
\hline $\begin{array}{l}\text { Química Nova na } \\
\text { Escola }\end{array}$ & $\begin{array}{c}\text { Ressignificando a Formação de Professores } \\
\text { de Química para a Educação Especial e } \\
\text { Inclusiva: Uma História de Parcerias } \\
\text { (ART 14) }\end{array}$ & $\begin{array}{l}\text { RETONDO, } \\
\text { C.G.; SILVA, G. } \\
\text { M. }\end{array}$ & B1/B2 & 2008 \\
\hline $\begin{array}{l}\text { Química Nova na } \\
\text { Escola }\end{array}$ & $\begin{array}{l}\text { O Diário Virtual Coletivo: Um Recurso para } \\
\text { Investigação dos Saberes Docentes } \\
\text { Mobilizados na Formação de Professores de } \\
\text { Química de Deficientes Visuais (ART 15) }\end{array}$ & $\begin{array}{l}\text { BENITE, A.M.C. } \\
\text { et al. }\end{array}$ & B1/B2 & 2014 \\
\hline
\end{tabular}

Fonte: as autoras, 2015.

Esta etapa da pesquisa também nos possibilitou a identificação dos pesquisadores que seriam entrevistados, pois, após esse levantamento pôde-se verificar os autores que possuem grupos de estudos consolidados sobre a temática investigada e que apresentaram uma produção relevante na área Ensino de Química/Ciências para a Deficiência Visual, sendo escolhidos três pesquisadores brasileiros.

Nossa pretensão com a realização das entrevistas foi de obter, através das informações fornecidas pelos interlocutores, suas compreensões sobre as necessidades formativas dos professores de Química para incluir os alunos com deficiência visual em suas aulas. Para obter tais informações, optamos pela realização da entrevista semiestruturada, que corresponde a um conjunto de questões elaboradas com base em teorias e hipóteses, sendo que novas questões podem surgir à medida que se recebem as respostas do entrevistado (TRIVIÑOS, 1987).

As produções identificadas na revisão bibliográfica, os dados construídos através das entrevistas e dos documentos, compõem o conjunto de informações denominado corpus de nosso estudo, que se encontra representado no Quadro 4. 
Quadro 4 - Corpus da Pesquisa

\begin{tabular}{|c|c|}
\hline Corpus da Pesquisa & Interlocutores/Documentos \\
\hline & 26 Trabalhos - Encontro Nacional de Ensino de Química (EQ) \\
Produções Nacionais & 20 Trabalhos - Encontro Nacional de Pesquisa em Educação em Ciências (EC) \\
& 05 Trabalhos - Banco de Dissertações e Teses da Capes (DT) \\
15 Artigos - Periódicos (ART)
\end{tabular}

Fonte: as autoras, 2015.

Para a análise dos dados, optamos pela metodologia de Análise Textual Discursiva (ATD) com base em Moraes e Galiazzi (2013), a qual corresponde a uma metodologia de análise de dados de natureza qualitativa "com a finalidade de produzir novas compreensões sobre os fenômenos e discurso. Insere-se entre os extremos da análise de conteúdo tradicional e análise de discurso" (MORAES; GALIAZZI, 2013, p. 7).

Esta metodologia envolve uma sequência recursiva de três componentes: i) a desconstrução do texto do corpus para a unitarização; ii) o estabelecimento das relações entre os elementos unitários através da categorização; iii) o captar emergente em que a nova compreensão é comunicada e validada, mediante a produção dos metatextos e das proposições construídas nessa etapa (MORAES; GALIAZZI, 2013).

Após delimitarmos o corpus de nossa pesquisa, e com posse dos materiais a serem analisados, iniciamos o ciclo de análise, por meio do processo de desconstrução e unitarização do corpus, em que os documentos analisados foram lidos na íntegra à procura de se destacar os seus elementos constituintes, ou seja, colocamos o foco nos detalhes e nas partes que compõem o texto para elaborarmos as unidades de significado.

Em seguida foi realizada a segunda etapa do ciclo da análise, que consistiu na categorização das unidades anteriormente construídas. Na metodologia de Análise Textual Discursiva, as categorias podem ser elaboradas por meio do método dedutivo, ou seja, as categorias são construídas antes mesmo de analisar o corpus, e são deduzidas a partir das teorias que fundamentam a pesquisa. Estas correspondem às categorias definidas a priori. As categorias também podem ser construídas mediante o método indutivo, a partir das unidades de significado, que provêm das construções teóricas que são produzidas a partir da análise do corpus. Tal processo se configura na construção de categorias emergentes. Ainda existe a possibilidade de adotar um terceiro método, denominado de categoria mista, o qual o pesquisador parte do conjunto de categorias definidas a priori e as complementa a partir das categorias emergentes da análise do corpus (MORAES; GALIAZZI, 2013). 
A terceira e última etapa da análise compreende a produção dos metatextos e a comunicação dos resultados por meio da construção de proposições. Em nossa pesquisa, os metatextos foram construídos por categoria, possibilitando assim uma nova compreensão do tema investigado a partir das fontes de informação, a qual foi expressa por meio das proposições elaboradas e discutidas em cada categoria, conforme apresentado a seguir.

\section{Categoria I: Conhecer os propósitos da Educação Inclusiva}

Nesta categoria discutimos a necessidade de promover na formação dos professores discussões sobre o acolhimento e o respeito aos diferentes alunos que se encontram nas escolas. Sendo que esta formação deve auxiliar os docentes a desconstruir certos pressupostos em relação a padrões, estereótipos, que perpetuam de modo implícito na realidade das instituições escolares, e nos demais contextos sociais.

\section{Proposição I: O docente deve reconhecer, aceitar e respeitar as diferenças presentes em sala de aula}

Respeitar as diferenças é a base de um ensino inclusivo, nesse sentido, é indispensável ao docente, reconhecer que todos os alunos têm sua própria história, suas crenças, suas necessidades, suas potencialidades, ou seja, suas características próprias. Portanto, diante da atual situação da Educação, que possibilita que todos, sem distinção, tenham acesso à escola, não se pode continuar formando professores idealizando um modelo "padrão de aluno", a Educação Especial na perspectiva Inclusiva "requer uma formação docente que envolva, para além do respeito, a compreensão da diversidade" (PIMENTEL, 2012, p.141). Tal concepção encontra-se evidenciada nas seguintes falas dos pesquisadores entrevistados:

[...] o tema da inclusão, que trabalha com a heterogeneidade, com a diversidade, com o respeito às múltiplas diferenças, para um curso de formação me parece que ele é um tema transversal. [...] (PQ 1).

Olha... eu acho que os principais resultados no geral é que a gente cada vez mais percebe, que não há limites, né? Que a maior dificuldade que essas pessoas encontram, é o preconceito nosso, e das pessoas com quem elas lidam. [...]

A gente poder acreditar no outro, mesmo que o nosso ponto de vista seja muito difícil, quem vai dizer se é possível ou não é a outra pessoa e não nós, né? (PQ 2).

Eu acho que nos currículos de formação inicial a gente poderia ter uma discussão maior sobre a alteridade e diferença. (PQ 3).

Diante das informações concedidas pelos pesquisadores, é possível observar que a inserção de discussões sobre o respeito às diferenças, deve ocorrer de forma ampla nos cursos de licenciatura, "tendo em vista que existe uma diversidade presente na sociedade que precisa ser compreendida e trabalhada" (PIMENTEL, 2012, p. 146). Tais aspectos, também se encontram evidentes nos relatos da produção acadêmica: 
[...] são necessárias ações compartilhadas capazes de orientar e qualificar os educadores na formação de sujeitos, valorizando a diversidade e fazendo valer o sentido da inclusão enquanto processo de reconhecimento e respeito das diferentes identidades, aproveitando-as para beneficiar a todos (ART 4).

[...] a aceitação de que todos os alunos possuem diferentes necessidades de aprendizagem e, por isso mesmo, não devem existir alunos especiais, já que cada um possui uma maneira de aprender (DT 4).

Nesse sentido, verifica-se que o objetivo de promover discussões sobre a diversidade de sujeitos que compõe a sala de aula e o respeito às diferenças individuais, não é o de focar nos casos de alunos com deficiência e nem utilizar a diferença como motivo de inferiorização, e sim ampliar o olhar do docente para compreender que "qualquer pessoa, por mais limitada que seja em sua funcionalidade acadêmica, social ou orgânica, tem uma contribuição significativa a dar a si mesma, às demais pessoas e à sociedade como um todo" (SASSAKI, 2005, p. 23).

Essas pesquisas apontam a necessidade de se discutir, com os futuros professores de Química, a relação entre o preconceito, a heterogeneidade de alunos e a igualdade de direitos, considerando todos os possíveis casos de exclusão. De modo que, proporcionar estas discussões sobre o respeito à diferença é uma das formas de promover mudanças nas concepções que ainda permanecem nas instituições escolares e na sociedade, as quais consideram que a estrutura e o funcionamento das escolas são mais confortáveis ao considerar a padronização, do que a diferença entre os estudantes (RODRIGUES, 2008).

Em síntese, verificamos que há um consenso entre os pesquisadores e os interlocutores das produções nacionais, quanto à urgência de propiciar uma reflexão nos cursos de formação inicial sobre o respeito às diferenças, a fim de possibilitar a compreensão do docente em torno do que se espera de um ensino na perspectiva Inclusiva e no caso específico do ensino de Química, que tem o objetivo de formar cidadãos críticos capazes de tomar decisões frente às questões de caráter científico e tecnológico, é imprescindível que o processo de ensino e aprendizagem decorra de atividades que possibilitem ao aluno a construção e utilização do conhecimento para além da sala de aula.

\section{Proposição II: Aproximar os licenciandos da realidade das escolas que atendem alunos com deficiência é um meio para que estes possam refletir sobre a atuação do professor no contexto inclusivo}

Os pesquisadores entrevistados relatam a importância de o professor durante sua formação inicial conviver com a realidade de instituições que atendem alunos com deficiência. Segundo os interlocutores esta situação permite a reflexão dos licenciandos, sobre 
as dificuldade e viabilidades encontradas no processo de inclusão destes estudantes, esta compreensão encontra-se evidenciada nas seguintes falas:

[...] levar para essa área do estágio essa temática que foi o que eu fiz, quando fiz o pós-doutorado, que eu não transformei a disciplina de prática só em torno disso, eu adicionei a questão da inclusão ao rol de temas que eles teriam que estudar na prática de ensino né? [...] esse processo de reflexão foi muito positivo (PQ 1).

[...] Então é o universo daquele sujeito social, quando a gente estende esse campo de estágio e esse aluno vai para lá, ele tem contato com aquele sujeito social, suas especificidades, numa instituição que está preparada só para ele [...] (PQ 3).

Diante dos registros apresentados, podemos inferir que estender o campo de Estágio, contemplando escolas de educação básica de ensino regular que tenham alunos com deficiência em sala de aula e que são acompanhados por especialistas nas salas de recursos, pode permitir mediante essa aproximação, que o futuro professor tenha condições de articular o conhecimento teórico sobre o assunto, refletir, compartilhar e discutir com os demais colegas meios de promover o acesso ao conhecimento e a participação efetiva dos discentes com deficiência. Possibilitando desta forma, "gerar experiência, como contribuição para a formação inicial e continuada dos envolvidos" (BENITE, 2011, p. 57).

Nessa mesma perspectiva dos pesquisadores, os interlocutores da produção nacional, destacam a necessidade de o docente ter um primeiro contato com alunos público alvo da Educação Especial, ainda em sua formação inicial. Estas concepções encontram-se evidenciadas nos seguintes trechos:

Vale ressaltar que somente a teoria não é suficiente para a formação de um professor inclusivo, mas é preciso que a prática, a metacognição e um primeiro "enfrentamento" façam parte de tal formação (ART 2).

Assim, para que haja um preparo para a prática inclusiva é necessário um contato direto com alunos de diferentes necessidades educativas especiais, tanto na teoria, quanto na prática, e o ideal é que esse contato ocorra ainda no período de graduação (EQ 22).

Essa perspectiva destacada pelos interlocutores da produção nacional vai ao encontro da assertiva descrita por Lopes (2013, p. 43), a qual destaca que os professores em formação, "necessitam de experiências que lhe permitam desenvolver atitudes e valores positivos que os encorajem a investigar, refletir e a encontrar soluções inovadoras para os desafios colocados pela diferença". Nessa perspectiva, destaca-se nas produções analisadas a importância de realizar a familiarização dos futuros docentes com a realidade inclusiva através do estágio supervisionado, pois, o contato com as escolas que promovam a inclusão de modo efetivo, com a participação ativa de todos os estudantes, independentemente de suas particularidades, no mesmo ambiente de estudo, configura-se como "uma ótima oportunidade para confrontar os conhecimentos estudados nos bancos da universidade" (VITALIANO; MANZINI, 2010, p. 
76). Bem como, pode permitir aos futuros professores perceber e refletir sobre o fato de que a existência de alunos público alvo da educação especial presente numa sala de aula regular, não significa necessariamente que está ocorrendo efetivamente a inclusão, pois na maioria das vezes, o que se verifica nas escolas são processos excludentes e que a inclusão deve ser avaliada pela participação efetiva de todos os estudantes no ambiente educacional.

Em síntese, é possível constatar diante das concepções apresentadas pelos interlocutores a importância de aproximar o professor que está em formação de sua realidade profissional, pois, desta forma, os licenciandos terão subsídios para discutir com seus colegas e professores suas experiências e as questões que envolvem esse contexto, como: diferentes formas de aprendizagem, de metodologia e de avaliação, os recursos educacionais disponíveis, o trabalho em conjunto com profissionais do atendimento especializado, entre outros; e assim, possam se tornar professores capazes de promover a inclusão e encarar os desafios da profissão.

\section{Categoria II: Conhecer as políticas públicas e o contexto histórico da Educação Especial e Inclusiva}

Discutimos nesta categoria as compreensões dos interlocutores sobre o entendimento necessário ao professor, no que diz respeito aos aspectos legais e históricos da Educação Especial e Inclusiva.

\section{Proposição I: Conhecer as principais políticas públicas mundiais e nacionais voltadas para a Educação Especial e Inclusiva, e refletir criticamente sobre os aspectos ético- políticos envolvidos neste contexto}

Mesmo com um conjunto significativo de políticas públicas desenvolvidas para atender ao contexto educacional inclusivo, muitas ainda são as dificuldades encontradas no desenvolvimento e na efetivação destas propostas. Diante disso, um dos pesquisadores entrevistados destaca a necessidade de incluir na formação de professores, discussões sobre os aspectos legais envolvidos na Educação Especial/Inclusiva. Segundo esse pesquisador, na formação é preciso uma disciplina, ou um conjunto de disciplinas que "tratem das questões legais sobre inclusão" (PQ 1).

Nessa perspectiva, Vitaliano e Manzini (2010), consideram relevante na formação dos professores, conhecimentos sobre a legislação desenvolvida para o atendimento educacional das pessoas com deficiência. Visto que, a falta deste conhecimento dificulta ao docente, compreender sua função nessa circunstância.

Nessa mesma perspectiva, os interlocutores dos trabalhos das produções nacionais, destacam a urgência de incluir na formação dos professores temas sobre as políticas públicas 
presentes no contexto educacional inclusivo, a fim de atender as demandas da sociedade atual. Podemos identificar tais apontamentos nos trechos a seguir:

[...] não houve enfoque relacionado às políticas educacionais no contexto inclusivo. Apesar disso, esse campo apresenta-se como um tema de grande urgência frente às necessidades e aos anseios da sociedade (DT 2).

[...] conteúdos que abordem a história da educação brasileira e como as políticas públicas afetam a educação [...] (DT 4) (EC 14).

Nesse sentido, Oliveira (2012, p. 269) ressalta que inserir na formação inicial conhecimentos sobre aspectos legais da inclusão, possibilita aos professores "reivindicarem os seus direitos e os dos alunos em termos de política de inclusão, por meio de respaldo legal", tendo desta forma condições para se posicionar de modo consciente, frente às situações presentes na realidade escolar.

Esses apontamentos demonstram a preocupação de propiciar na formação inicial um diálogo, que integra a análise e a compreensão dos aspectos éticos contidos nas políticas públicas, sobre os direitos das pessoas com deficiência ao ensino regular, dentre as políticas públicas sobre inclusão destacam-se a LDB 9.394/96, a Declaração de Salamanca (1994), e mais recentemente a Lei Brasileira de Inclusão da Pessoa com Deficiência (2015). Segundo Vitaliano e Manzini (2010, p. 80), os textos dispostos nos dois primeiros documentos "apresentam as condições que a escola deve prover para atender às necessidades educacionais especiais".

Diante dos apontamentos apresentados pelos interlocutores nesta proposição, podemos inferir que, quando os princípios éticos e políticos da Educação Inclusiva forem discutidos nos cursos de formação de professores, estes poderão se tornar "capazes de subsidiar uma atuação docente autônoma e comprometida com o projeto de inclusão" (OLIVEIRA, 2012, p. 273).

\section{Categoria III: Conhecer sobre as deficiências}

O conhecimento das características próprias da deficiência pode auxiliar o docente a identificar, e propor meios de atender as necessidades que seu aluno apresenta, bem como, romper com concepções equivocadas e preconceituosas sobre as potencialidades e limitações dos alunos com deficiência. Desse modo, discutimos nesta categoria aspectos referentes aos saberes docentes sobre as diferentes situações de deficiência. 


\section{Proposição I: O conhecimento sobre as deficiências permite ao docente identificar e distinguir, as necessidades comuns e específicas de seus alunos}

Os pesquisadores colaboradores da pesquisa destacam que o conhecimento sobre as deficiências permite ao docente identificar as necessidades comuns e as que são próprias da deficiência que seu aluno apresenta, conforme proferido nas seguintes expressões:

\footnotetext{
É uma tendência generalizadora que o professor faz em relação à ideia de deficiência ou de necessidade especial; de que todo aluno; ele como um todo tem necessidade especial né? [...] (PQ 1).
}

Quando a gente começou o trabalho a gente viu que as dificuldades que eles apresentavam eram muito grandes, e a gente ficava meio assustado, mas depois a gente foi percebendo que essas dificuldades não eram exclusivamente deles. Eram dificuldades dos alunos colegas deles, da escola, do nível deles (PQ 2).

[...] a presença dessas ditas "minorias", pode ser capaz de alertar a escola para àqueles que estão no banco, que são considerados como alunos regulares, que também não aprendem nada (PQ 3).

Diante desses relatos, podemos inferir que os professores podem ter dificuldades em compreender que o aluno possui algumas necessidades que são decorrentes da deficiência que ele apresenta, no entanto, estas necessidades não o impedem de aprender e realizar as atividades, desde que lhe seja proporcionado condições de atuação e acessibilidade. Tendo em vista romper com essa concepção equivocada sobre as necessidades das pessoas com deficiência, Vitaliano e Manzini (2010) afirmam que inserir nos cursos de formação de professores, discussões a respeito das características das deficiências podem auxiliar o docente a construir concepções mais positivas acerca do aprendizado dos estudantes com deficiência e a "identificar os procedimentos de ensino que podem ser comuns a todos os alunos, bem como aqueles que realmente necessitam ser diferentes" (VITALIANO; MANZINI, 2010, p. 70).

Ao encontro das concepções dos pesquisadores, os interlocutores da produção nacional destacam que é preciso fornecer na formação docente conhecimentos sobre os estudantes com necessidades específicas, pois, quando estes não são contemplados com a devida importância, geram uma lacuna na formação dos professores e podem levar a dificuldades para promover a inclusão, conforme explicitado nos seguintes relatos:

[...] os professores não sabem lidar com alunos especiais, o que acaba acarretando um prejuízo pedagógico, um déficit cultural, nos alunos (ART 1).

[...] muitos professores só adquirem informação e formação sobre alunos com necessidades educacionais especiais quando se encontram com eles na sala de aula (ART 4).

Novos saberes, saberes específicos para um público especial devem ser acrescentados à formação (EC 16).

Nesse sentido, Vitaliano e Manzini (2010) afirmam que os conhecimentos a serem contemplados nos cursos de formação, no que se refere às características dos alunos público 
alvo da Educação Especial, devem promover uma reconfiguração das concepções docentes sobre necessidades específicas. Visto que "temos uma história de aprendizagem social que, na maioria das vezes, nos ensinou a considerar, especialmente as pessoas com necessidades específicas, de modo generalizado, deficientes “em tudo"”' (VITALIANO; MANZINI, 2010, p. 55).

Esses autores ainda recomendam que a formação dos professores deve abordar os conhecimentos sobre as categorias de deficiência, com cuidado, visto que, muitas vezes, o modo como alguns aspectos são utilizados para caracterizar as deficiências, acaba por favorecer o preconceito e a segregação. Deste modo, a formação deve promover reflexões ao futuro docente para compreender que as limitações e fragilidades atribuídas a uma pessoa com deficiência decorrem diretamente da estrutura social, que é uma construção modificada e produzida pelo ser humano.

O entendimento que a deficiência é um fenômeno que só pode ser compreendido socialmente devem ser tomados como ponto de partida para organizar seus procedimentos didáticos, "incluindo nestes a seleção dos recursos materiais e de apoio ao processo de aprendizagem, assim como a forma de interação que deve estabelecer com seu aluno" (VITALIANO; MANZINI, 2010, p. 75).

\section{Proposição II: Conhecer as características das deficiências possibilita ao docente identificar as potencialidades e romper com o preconceito sobre a capacidade de aprendizado do aluno com necessidades específicas}

Os docentes, quando não têm em sua formação os conhecimentos sobre as características da deficiência, levam para sala de aula concepções equivocadas e preconceituosas, fato que dificulta a inclusão e a participação dos alunos com deficiência na sala de aula regular. Nesse sentido, os pesquisadores relatam:

[...] no caso essas disciplinas que eu te falei a parte elas teriam que esclarecer, seria um momento separado no curso em que os licenciandos se matriculariam para discutir a inclusão, para discutir a deficiência, para discutir tudo isso que eu estou te falando, porque realmente essa ideia que se tem, que ele todo, e tudo que ele faz representa uma necessidade especial, não é assim! Não deve ser assim! (PQ 1).

[...] quem vai dizer se é possível ou não é a outra pessoa e não nós, né? Eu não te conheço, mas eu não posso afirmar que você é uma nadadora olímpica! Se tiver condições, se tiver algum estímulo que você sinta a necessidade e interesse em fazer isso, você pode se tornar, depende de você e não de mim. [...] (PQ 2).

A partir desses registros compreendemos que o professor precisa ter o entendimento de que o aluno com deficiência tem condições de aprender, pois "se os professores desenvolvem uma visão de que seu aluno é incapaz, eles terminam por abandoná-lo, não favorecendo situações de interação que possibilitem o avanço cognitivo e o desenvolvimento desse sujeito" (PIMENTEL, 2012, p. 139). 
Ao encontro desta perspectiva os interlocutores das produções nacionais destacam que por não terem o conhecimento necessário sobre as deficiências, principalmente de que a mesma é um fenômeno social, e por não acreditarem na capacidade de aprendizado dos estudantes, os professores se sentem impotentes ao atuar em uma sala de aula com a presença de alunos com necessidades educacionais específicas, essa "sensação de impotência é aumentada pelos estigmas que são imputados pelo preconceito social com relação à diferença” (PIMENTEL, 2012, p.146). As concepções dos interlocutores que compartilham esse entendimento encontram-se evidenciadas nos seguintes fragmentos:

Os sentimentos de ansiedade e rejeição do docente para com estes discentes surgem do pouco ou nenhum conhecimento sobre estes alunos em sua formação inicial (ART 4).

[...] o que necessita ficar claro para o professor, é que estes alunos com deficiência visual são tão capazes como qualquer outro aluno. Não devemos interpretar que, por causa da deficiência visual, esse aluno seja menos capaz (DT 1).

[...] necessidade de orientação, palestras e cursos de capacitação, tanto para formação do profissional quanto para desmistificação das limitações das deficiências, para pensar uma universidade diferente, uma universidade diversa [...] (EQ 18).

Nesse sentido, podemos compreender que a falta de conhecimento sobre as necessidades específicas, decorrentes da deficiência que seu aluno apresenta, e a visão preconceituosa dos docentes, dificulta o processo de aprendizado destes. Ao contrário, quando o docente tem o reconhecimento das potencialidades das pessoas com deficiência, desenvolve sua prática visando promover um ambiente favorável e acessível para a aprendizagem de todos os estudantes, tendo em vista minimizar as situações de exclusão e o preconceito em sala de aula.

Assim, diante das compreensões expressas pelos interlocutores nesta proposição, compreendemos que a percepção das potencialidades e das necessidades específicas dos alunos com deficiência, auxilia o professor a planejar sua prática pedagógica e a promover uma estrutura educacional visando a melhor forma de incluir estes estudantes, sem que estes sejam prejudicados e somente estejam presentes fisicamente em sala de aula, sem participar de modo ativo no processo de aprender, evitando assim que ocorra o fenômeno da pseudoinclusão (PIMENTEL, 2012). Consideramos que esse pensar uma nova estrutura educacional poderia fazer o professor buscar subsídios para atender esses alunos para além da integração em sala de aula.

\section{Categoria IV: Saber avaliar}

A avaliação do processo de aprendizagem é muito importante no processo de inclusão educacional, pois, esta deve ser compreendida pelo docente como um modo de diagnosticar problemas e a partir disso planejar alterações em sua prática visando à melhoria do ensino. 
Devido a estas circunstâncias, discutimos nesta categoria os aspectos relativos à formação do professor para realizar a avaliação na perspectiva da Educação Inclusiva.

\section{Proposição I: O professor deve compreender a avaliação como um processo que o permite diagnosticar as diferentes situações de aprendizagem e com isso planejar novas ações a fim de aprimorar sua prática para o atendimento à diversidade de alunos.}

$\mathrm{Na}$ concepção dos interlocutores das produções nacionais, a avaliação deve ser compreendida pelos professores como um processo no qual além de avaliar o desempenho de seu aluno com deficiência, o docente avalie se a sua prática pedagógica e o seu método de avaliação estão condizentes com as necessidades específicas do estudante. As afirmações dos interlocutores que compreendem essa perspectiva encontram-se nos seguintes trechos:

Essa participação deve ser revista pelos professores e gestores de escola que devem avaliar as suas estratégias metodológicas e suas avaliações [...] (DT 2).

A dificuldade do professor da educação básica é a falta de preparo/capacitação profissional, falta de infraestrutura das escolas e escassez de materiais didáticos, bem como do conhecimento de uma forma de avaliação que esteja adaptada às condições dos alunos com deficiências. (EC 12).

[...] elaborar critérios avaliativos que permitam a coleta de informações que sirvam de base para o planejamento de novas ações e o aprimoramento do atendimento à diversidade (EQ 16) (EC 13).

Este entendimento vai ao encontro da perspectiva defendida por Minetto (2008), que considera que a avaliação deve ser compreendida, como um processo pelo qual o professor reflete sobre sua prática pedagógica, e "revê as ações educativas que estão sendo desenvolvidas e até que ponto o fracasso do aluno não está diretamente relacionado a ela (a prática pedagógica) ou a sua forma de avaliar" (MINETTO, 2008, p. 83). Tal processo permite ao professor rever sua prática e promover intervenções a fim de atingir os objetivos propostos.

Enfatizamos ainda que, o processo avaliativo não deveria ser reduzido à atribuição de uma nota, o docente deveria considerar todos os fatores que envolvem o aprendizado e o desenvolvimento de seus alunos e sentir-se corresponsável dos resultados obtidos por eles. Portanto, se o professor tiver este entendimento e o incorporar em sua prática, estará auxiliando a escola a realizar sua função de transpor conhecimentos e valores para promover uma sociedade mais justa, atendendo aos propósitos da Educação Inclusiva. 
Proposição II: O futuro professor deve discutir e refletir na formação inicial sobre o processo de avaliação, métodos e recursos diversificados, que contemplem as necessidades específicas de seus alunos

No que se refere aos conhecimentos necessários para que o professor saiba avaliar o aluno com deficiência, no contexto da Educação Inclusiva, um dos pesquisadores (PQ 1), relata como essencial que o docente saiba adotar em sua prática métodos avaliativos que atendam a necessidade do aluno, e explicita isto através de sua experiência como aluno com deficiência visual, em que seu professor lhe permitia realizar as atividades avaliativas em momentos distintos aos de seus colegas, fazendo uso de recursos e métodos específicos a fim de atender a sua realidade. Esse entendimento do pesquisador vai ao encontro da proposta defendida por Aranha (2002), que ressalta que devem ser fornecidas aos estudantes com deficiência, metodologias avaliativas que atendam às suas necessidades, pois, desta forma, "ele não se diferenciará dos demais, no sentido de que estará igualmente "fazendo" a prova" (ARANHA, 2002, p. 29).

Nessa perspectiva, os interlocutores da produção nacional, compreendem que somente com a utilização de metodologias e recursos diversificados no processo avaliativo, o aluno terá condições de demonstrar o seu desenvolvimento, e os objetivos necessários para o seu aprendizado. Para isso os professores também necessitam avaliar se as suas estratégias metodológicas atendem essa realidade. Estas compreensões encontram-se evidenciadas nos seguintes fragmentos:

[...] os alunos com deficiência visual, refletem a necessidade de um pensar inclusivo, ou seja, que eles consigam se sentir participativos efetivamente na sala de aula regular. [...]. Essa participação deve ser revista pelos professores e gestores de escola que devem avaliar as suas estratégias metodológicas e suas avaliações para que o aluno tenha uma aprendizagem significativa ${ }^{2}$ (DT 2).

Só depois de oportunizar à criança a exploração ou imersão em ambientes e materiais diversificados, é que fará sentido avaliar os potenciais intelectuais (DT 5).

[...] avaliação, entendida como um processo que não pode se limitar à utilização das tradicionais provas, pelo contrário, precisa se basear em uma diversidade de instrumentos (EQ 24).

Nesse sentido, Christofari (2012, p. 7) afirma que na perspectiva da inclusão, a avaliação da aprendizagem "pode ser uma das alternativas para afrouxar os nós que prendem a escola em uma prática cotidiana mais preocupada com a disciplina e com o controle dos alunos, mais preocupada com o resultado do que com o processo". Para tanto, "o professor precisa realizar diferentes atividades e aplicar diversos instrumentos de avaliação em

\footnotetext{
${ }^{2}$ No referido trabalho analisado, compreende-se por aprendizagem significativa aquela que permite ao aluno explorar o desconhecido por meio de um conhecimento por ele construído no ambiente escolar e em outros espaços educativos.
} 
diferentes momentos do período letivo que possam revelar como e o quê o aluno está aprendendo" (PIMENTEL, 2012, p. 144).

Portanto, além de formas diferenciadas de avaliar, existe a necessidade de o docente conhecer sobre as características da deficiência que seu aluno apresenta, para selecionar as metodologias e os recursos educacionais, que possam favorecer o aluno a realizar as atividades avaliativas assim como os demais colegas.

\section{Categoria V: Saber trabalhar em equipe}

Muitas são as tarefas atribuídas ao professor da sala regular para incluir e garantir ao aluno com deficiência acesso ao conhecimento, assim, o trabalho em conjunto com demais profissionais é muito importante para a melhoria do ensino e da prática docente, e tendo em vista garantir a inclusão de estudantes com deficiência nas escolas regulares, discutimos nesta categoria os saberes necessários para o docente realizar de forma eficiente o trabalho em equipe.

Proposição I: O docente deve saber trabalhar juntamente com os pais e com demais profissionais do atendimento especializado, compreendendo as funções que cada um deve desempenhar para contribuir com o aprendizado do aluno com deficiência

A Educação Especial na perspectiva Inclusiva requer que o professor da sala regular trabalhe de modo cooperativo com os profissionais do atendimento especializado, visando proporcionar melhores formas de acesso ao conhecimento ao aluno com deficiência. Assim sendo, é importante que o professor da sala regular não atribua a responsabilidade somente ao professor da sala de recursos e compreenda que ambos devem trabalhar em equipe visando proporcionar ao aluno melhores condições de aprendizagem. Tais compreensões encontramse evidenciadas nos seguintes relatos:

[...] acontece muitas vezes é que o professor comum, se é que a gente pode chamar assim, ele entende que o aluno com necessidade especial é uma questão da "sala de recurso" [...] (PQ 2).

A gente nota que há uma grande confusão entre os papeis desses agentes, quem são os mediadores do conhecimento e quem são os intermediadores?...Quem deve fazer a adaptação de uma prova, por exemplo, é o professor regente, ou é o professor de apoio? Nisso ainda temos gaps né?! (PQ 3).

Neste sentido, Santos (2003) afirma que com o movimento da Educação Especial na perspectiva Inclusiva, ocorre a transformação da cultura das instituições escolares, e desta forma adota-se uma cultura orientada pela e para a inclusão, que deve envolver todos os segmentos da comunidade escolar na responsabilidade do aprendizado e na solução de problemas. 
Nessa perspectivam os interlocutores da produção nacional enfatizam que esta reorganização traz a necessidade de o professor trabalhar conjuntamente com os profissionais do atendimento especializado, de modo a propiciar oportunidades de aprendizado que atendam às necessidades de seus alunos com deficiência. Essa perspectiva encontra-se evidenciada nos fragmentos a seguir:

O essencial é que devemos trabalhar conjuntamente, professor da sala de aula com professor da sala de apoio, e não cada um no seu lugar. (DT 1).

O ensino regular e a educação especial devem se unir para satisfazer as necessidades educacionais de todos, oferecendo as mesmas oportunidades, principalmente sobre o enfoque subjetivo, dos próprios deficientes (EQ 6).

[...] percebeu-se a necessidade de um maior planejamento em relação às atividades realizadas nas aulas de Química, uma vez que a professora especializada poderia auxiliar o professor da sala regular no desenvolvimento de materiais específicos para as aulas de Química (EQ 8).

Assim, é possível compreender que através do trabalho em conjunto entre o professor da sala regular e o professor especialista, estes seriam capazes de desenvolver juntos, uma intervenção eficiente para que o aluno atinja o sucesso em seu aprendizado. Possibilitando desta forma o acesso ao conhecimento, por parte do aluno e o respeito às suas particularidades. Ao encontro desta perspectiva, Duk (2002, p. 23) afirma que "o trabalho colaborativo visa a elaboração de um projeto educacional conjunto, que assegure coerência e continuidade à ação educacional que cada docente desenvolve na instituição educacional”.

Diante dos apontamentos expostos nessa proposição podemos compreender que se os professores não tiverem esse entendimento de que a Educação Especial não deve acontecer de modo paralelo e sim juntamente com o ensino regular e "continuarem atuando isoladamente não alcançaremos a utopia da inclusão escolar: meninos e meninas, com ou sem deficiência aprendendo e convivendo juntos na escola" (ANTUNES; GLAT, 2011, p. 12).

Nesse sentido, entendemos que a falta de articulação, tem relação com os diversos problemas enfrentados pelas instituições escolares, como: a falta de estrutura e materiais, um número reduzido de professores especializados e a falta de organização institucional para que os docentes tenham um tempo destinado, para que em equipe, possam discutir e planejar juntos propostas inclusivas e de trabalho em equipe (BENITE, 2011). Bem como, as especificidades das políticas de inclusão adotadas em cada unidade federativa do Brasil, que pode afetar esse trabalho em equipe, que consideramos de extrema importância para garantir de forma efetiva a Educação Inclusiva. 
Proposição II: Estabelecer parcerias entre Universidade, Escolas, Secretarias de Educação e Centros de AEE, propicia o diálogo entre as diferentes esferas, promovendo novas compreensões a respeito da Educação Inclusiva e a Formação docente, auxiliando deste modo para a formação de profissionais mais capacitados

Conforme destacamos anteriormente a Educação Especial na perspectiva da Inclusão, requer que os profissionais atuem em equipe visando promover a participação e o desenvolvimento dos alunos com deficiência, neste sentido os pesquisadores enfatizam a necessidade de expandir as discussões realizadas na Universidade para a sociedade. Uma das formas é promover, por meio de grupos de estudo, parcerias entre a Universidade e a Escola, para que desta forma possa se estabelecer um diálogo, a fim se sanar dúvidas, compartilhar experiências significativas para a inclusão, e propor estratégias e ações, com intuito de assegurar que a Educação Inclusiva realmente aconteça. As falas a seguir expressam essa concepção:

[...] Isso tem que ser expandido para fora da universidade, porque a gente vem pensando em inclusão muito dentro da questão escolar, primeiro ensino médio né? Ensino básico, médio...fundamental e médio, mas esses alunos vão chegar a Universidade né? E depois vão para o mercado de trabalho (PQ 1).

[...] uma parceria Universidade- Escola, faz com que esse professor venha até nos, nós vamos até ele, nós temos um espaço uma sala de reuniões, uma sala de estudo dentro da Secretaria de Educação aqui do Estado. Então uma semana a gente vai para lá, outra semana eles vêm para a Universidade e a gente vai fazendo essa troca aí (PQ 3).

Ao encontro dessa perspectiva, Vitaliano e Valente (2010) defendem que o processo de inclusão educacional requer uma compreensão consciente do fazer pedagógico, que envolve "uma análise crítica da organização escolar, reflexão e busca de conhecimentos constantes, por meio de discussão com seus pares e junto às fontes de conhecimentos já sistematizados" (VITALIANO; VALENTE, 2010, p. 44). Para estas autoras, promover essa discussão entre diferentes grupos, torna-se essencial para que estes profissionais possam agir frente às mudanças educacionais decorrentes da proposta inclusiva.

Nesse sentido, os interlocutores da produção nacional, também ressaltam que as relações entre Universidade e Escola, podem, além de estabelecer parcerias colaborativas para a formação de professores na perspectiva inclusiva, enfrentar "a distância histórica entre cursos de formação inicial de professores e os profissionais da educação básica como modo de contribuir para a aprendizagem dos participantes dos processos formativos" (ART 13). Conforme destacam os trechos a seguir:

[...] Defendemos, portanto, que os saberes docentes se estabeleçam sempre na relação com o outro, isto é, na interação entre os sujeitos desta investigação (ART $15)$.

Promover o diálogo entre professores constituiu o ato de entrar na Universidade, momento que consideramos de aprendizagem mútua da autoridade partilhada, e por isso intencionalmente afastada do discurso de autoridade, intencionando parceria e cumplicidade (EQ 7). 
De acordo com Mantoan (2007), para atingirmos um ensino de qualidade que contemple a Educação Especial na perspectiva Inclusiva, é necessário aumentar e promover entre os diferentes contextos envolvidos, apoio e parcerias para enfrentar essa tarefa que é de todos. Deste modo, compreendermos que os grupos de estudo entre Universidades, Escolas e Centros de AEE, possibilitam que estes profissionais possam juntos prever formas de melhorar a formação de professores para responder a este contexto.

\section{Considerações finais}

Mediante as discussões tecidas neste trabalho, compreendemos que para superar os desafios impostos pela Educação Inclusiva e possibilitar ao professor de Química a inclusão dos seus alunos, independente das necessidades específicas que apresentam, os cursos de formação devem promover reflexões sobre o respeito às diferenças, que possibilitem ao docente a compreensão dos objetivos da Educação Especial na perspectiva Inclusiva. Além disso, podemos verificar a importância de aproximar o professor que está em formação de sua realidade profissional, para que desta forma, possa refletir sobre o respeito aos diferentes estudantes com compõem a sala de aula, e as dificuldades e possibilidades de se promover a inclusão.

Consideramos que é necessário fornecer aos professores conhecimentos sobre as questões políticas e históricas presentes na Educação Especial e Inclusiva, o que possibilita que estes compreendam os acontecimentos históricos e políticos que influenciam na inclusão de estudantes com deficiência no contexto atual, bem como, proporcionar aos mesmos conhecimentos necessários para buscar a garantia dos seus direitos e de seus alunos.

Além disso, compreendemos que o professor deve ser formado para trabalhar em equipe, para junto com os demais profissionais, se tornarem capazes de buscar soluções para a melhoria do Ensino e da Formação de Professores, visando a inclusão dos estudantes com deficiência e acesso aos conhecimentos científicos abordados na disciplina de Química, relevantes para sua atuação na sociedade.

Diante das discussões realizadas no decorrer desse trabalho, podemos concluir que os resultados encontrados vão ao encontro de alguns estudos já realizados sobre a formação de professores na perspectiva inclusiva (ARANHA, 2002; VITALIANO; VALENTE, 2010; BENITE, 2011; ANTUNES; GLAT, 2011; CAMARGO, 2012), no sentido de destacar que a ausência de conhecimento do professor sobre as características das deficiências, o não reconhecimento das potencialidades destes estudantes, a falta de recursos didáticos a fim de atender as necessidades advindas das situações de deficiência, a não flexibilização do 
currículo e da avaliação, podem ser considerados fatores determinantes para barreiras atitudinais, e práticas pedagógicas distantes dos propósitos da Educação Inclusiva.

\section{Referências}

ANTUNES, K. C. V; GLAT, R. Formação de professores na perspectiva da Educação Inclusiva: os cursos de pedagogia em foco. In: PLETSCH, M. D.; DAMASCENO, A. (Org.). Educação Especial e Inclusão Escolar: reflexões sobre o fazer pedagógico. Seropédica: EDUR/UFRRJ, 2011. p. 188-201.

ARANHA, M. S. F. Formando Educadores para a Escola Inclusiva. Brasília: Ministério da Educação, 2002. Disponível em:

$<$ http://cdnbi.tvescola.org.br/resources/VMSResources/contents/document/publicationsSeries/ 130746FormandoEducadoresEscola.pdf>. Último acesso em: 20 out. 2016.

BENITE, C. R. Formação e Docência em Rede Social: Estudos sobre a Inclusão Escolar e o Pensar Comunicativo. Tese de Doutorado em Química - Universidade Federal de Goiás, Goiânia. 2011.

BRASIL. Política Nacional de Educação Especial na perspectiva da Educação Inclusiva. Brasília: Ministério da Educação, 2008. Disponível em:

$<$ http://portal.mec.gov.br/arquivos/pdf/politicaeducespecial.pdf>. Último acesso em: 20 out. 2016.

BRASIL. Parâmetros Curriculares Nacionais: Ensino Médio. Brasília: Ministério da Educação, 2000. Disponível em: < http://portal.mec.gov.br/seb/arquivos/pdf/blegais.pdf > . Último acesso em: 21 out. 2016.

BRASIL. Lei Brasileira de Inclusão da Pessoa com Deficiência :Estatuto da Pessoa com Deficiência. Brasília: Casa Civil, 2015.

Disponível em: < http://www.planalto.gov.br/ccivil_03/_ato2015-2018/2015/lei/113146.htm> Último acesso em 03 nov. 2017.

CAMARGO, E. P. Saberes docentes para a inclusão do aluno com deficiência visual em aulas de Física. São Paulo: Ed. UNESP, 2012.

LEITE, L. P.; SILVA, A. M. Práticas Educativas: Adaptações Curriculares. In: CAPELLINI, V. L. M. F. (org.). Práticas em educação especial e inclusiva na área da deficiência mental. Bauru: Ministério da Educação, 2008. p. 16-25.

CHRISTOFARI, A. C. Avaliação da Aprendizagem e Inclusão Escolar: Relações Possíveis. In: Seminário de Pesquisa em Educação da Região Sul, 9., 2012, Caxias do Sul.

Anais...Caxias do Sul: UCS, 2012.

DUK, C. Educar na diversidade: material de formação docente. Brasília: Ministério da Educação, 2006. Disponível em:

<http://portal.mec.gov.br/seesp/arquivos/pdf/educarnadiversidade2006.pdf> Último acesso em: 21 out. 2016.

FERREIRA, N. S. A. As pesquisas denominadas “Estado da Arte”. Educação \& Sociedade, n79, p. 257-272, 2002. Disponível em: <http://www.scielo.br/pdf/es/v23n79/10857.pdf> Último acesso em: 20 out. 2016. 
LIPPE, E. M. O.; CAMARGO, E. P. Ensino de Ciências e Deficiência Visual: Uma investigação das percepções da professora de ciências com relação à inclusão. In: Jornada de Educação Especial: Educação Especial e o uso das tecnologias da informação e comunicações em práticas pedagógicas inclusivas, 10., 2010, Marília. Anais...Marília, 2010.

LÜDKE, M.; ANDRÉ, M. E. D. A. Pesquisa em Educação: Abordagens Qualitativas. 2. ed. Rio de Janeiro: EPU, 2013.

MANTOAN, M. T. E. Igualdade e diferenças na escola: como andar no fio da navalha. Educação, Santa Maria, vol. 32, n 2, p. 319-326, 2007. Disponível em:

<http://www.redalyc.org/pdf/1171/117117241004.pdf> Último acesso em: 20 out 2016.

MELLO, E. M. O professor, Alunos Cegos e a Linguagem Matemática. Revista Paranaense de Ensino de Matemática. Campo Mourão, v.2, n. 2, p. 132-143, jan. 2013. Disponível em: < http://www.fecilcam.br/revista/index.php/rpem/issue/view/31> Último acesso em: 20 out. 2016.

MINETTO, M. F. Currículo na Educação Inclusiva: entendendo esse desafio. 2. ed. Curitiba: IBIPEX, 2008.

MORAES, R.; GALIAZZI, M. C. Análise Textual Discursiva. 2. ed. Ijuí: Unijuí, 2013.

NUNES, B. C.; DUARTE, C. B. PADIM, D. F.; MELO, I. C.; ALMEIDA, J. L.; TEIXEIRA JÚNIOR. J. G. Propostas de atividades experimentais elaboradas por futuros professores de Química para alunos com deficiência visual. In: Encontro Nacional do Ensino de Química, 10., 2010. Brasília. Anais... Brasília: UNB, 2010.

OLIVEIRA, I. A. Práticas municipais de inclusão da pessoa com deficiência no estado do Pará. In: MIRANDA, T. G., GALVÃO FILHO, T. A. O professor e a Educação Inclusiva: Formação, Práticas e Lugares. Salvador: EDUFBA, 2012. p. 267- 287.

PIMENTEL, S. C. Formação de professores para a inclusão: Saberes necessários e percursos formativos. In: MIRANDA, T. G.; GALVÃO FILHO, T. A. O professor e a Educação Inclusiva: Formação, Práticas e Lugares. Salvador: EDUFBA, 2012. p. 139-157.

RODRIGUES, D. Desenvolver a Educação Inclusiva: Dimensões do Desenvolvimento Profissional. Inclusão: Revista da Educação Especial, Brasília, v. 4, n. 2, p. 8-16, 2008.

SANTOS, W. L. P.; MORTIMER, E. F. A dimensão social do Ensino de Química- Um estudo Exploratório da visão de professores. In: Encontro Nacional de Pesquisa em Educação em Ciências, II, 1999, Valinhos. Anais... São Paulo, 1999.

SANTOS, M. P. O papel do Ensino Superior na Proposta de uma Educação Inclusiva. Revista Movimento, Rio de Janeiro, n. 7, p. 78-91, 2003.

SASSAKI, R. K. Inclusão: o paradigma do século 21. Inclusão: Revista da Educação Especial, Brasília, ano 1, n. 1, p. 19-23, 2005.

SILVA, T. T. Documentos de Identidade: Uma introdução às teorias do currículo. Belo Horizonte: Autêntica, $3^{\mathrm{a} e d .,} 2010$.

TRIVIÑOS, A. N. S. Introdução à Pesquisa em Ciências Sociais: a Pesquisa Qualitativa em Educação. $1^{a}$ ed. São Paulo: Atlas, 1987. 
VITALIANO, C. R.; VALENTE, S.M.P. A formação de professores reflexivos como condição necessária para a inclusão de alunos com necessidades educacionais especiais. In: VITALIANO, C. R. Formação de professor para a inclusão de alunos com necessidades educacionais especiais. Londrina: Eduel, 2010. p. 38-48.

VITALIANO, C.R.V.; MANZINI, E.J.A Formação Inicial de Professores para a Inclusão de Alunos com Necessidades Educacionais Especiais. In: VITALIANO, C.R. Formação de professor para a inclusão de alunos com necessidades educacionais especiais. Londrina: Eduel, 2010. p. 50-112.

\section{SOBRE AS AUTORAS}

TATIANE ESTÁCiO DE PAULA. Mestre em Educação em Ciências pela Universidade Federal do Paraná (2015), possui Licenciatura em Química pela Faculdade Estadual de Filosofia, Ciências e Letras de União da Vitória (2012). Tem experiência na área de Ensino de Química, atuando principalmente nos seguintes temas: Educação Inclusiva no Ensino de Química, Materiais Alternativos para o Ensino de Química, Experimentação no Ensino de Química, Formação Professores de química para Inclusão de Alunos com Deficiência Visual. Atualmente é professora de Química do Instituto Federal Catarinense, Campus Avançado Sombrio (2016). ORCID iD: 0000-0002-9337-8293.

ORLINEY MACIEL GUIMARÃES. Doutora em Ciências pela USP/São Carlos (1997), mestre em Ciências pela USP/FFCLRP de Ribeirão Preto (1991), possui Licenciatura em Química pela Universidade Federal de Uberlândia (1988). Atualmente é professora Titular do Departamento de Química da Universidade Federal do Paraná, onde atua desde 1992. Foi coordenadora do Curso de Graduação em Química da UFPR de 2014-2017. Foi coordenadora do Programa de Pós-Graduação em Educação em Ciências e em Matemática da UFPR onde atuou de 2010 a 2016, orientando 13 dissertações de mestrado. Atualmente é professora permanente no Programa de Pós-Graduação em Educação da UFPR (mestrado e doutorado) na Linha de Pesquisa: Cultura, Escola e Ensino e coordenadora do Mestrado Profissional em Química em Rede Nacional (PROFQUI) na UFPR. Coordena o Núcleo de Educação em Química da UFPR desde 2000, foi Tutora do Grupo PET-Química (2008-2014). Atua na área de Ensino de Química com interesse nos seguintes temas: formação inicial e continuada de professores, currículo e avaliação, experimentação no ensino de ciências e Ensino de Ciências para Deficientes Visuais. ORCID iD: 0000-0003-4762-4884.

CAMILA SILVEIRA DA SILVA. Licenciada em Química pelo Instituto de Química da Unesp de Araraquara. Mestre e Doutora em Educação para a Ciência pela Faculdade de Ciências da Unesp de Bauru. Tem experiência na área de Ensino de Ciências e de Química, trabalhando com os seguintes temas: Museus de Ciências, Formação de Professores, Relação Ciência e Arte e Materiais Didáticos. Professora Adjunta no Departamento de Química, da Universidade Federal do Paraná. Professora do Programa de Pós-Graduação em Educação em Ciências e em Matemática e do Programa de Mestrado Profissional em Química em Rede Nacional da UFPR. Professora Coordenadora do PIBID-Química UFPR. ORCID iD: 00000002-6261-1662.

Recebido: 20 de outubro de 2016.

Revisado: 21 de agosto de 2017.

Revisado: 05 de novembro de 2017.

Aceito: 06 de fevereiro de 2018. 